KatHLEen Gobush (๑ orcid.org/0000-0003-3407-2419)

AfESG Red List Lead, Center for Conservation Biology, University of Washington, Seattle, USA

Fiona MAISELS (৫ orcid.org/0000-0002-0778-0615) Wildlife Conservation Society, New York, USA, and Faculty of Natural Sciences, University of Stirling, Stirling, UK

SAM WASSER (○ orcid.org/0000-0002-2678-1904) Center for Conservation Biology, University of Washington, Seattle, USA

BENSON OKITA-OUMA (๑ orcid.org/0000-0001-7184-7303) AfESG Co-Chair, Save the Elephants, Nairobi, Kenya

Rов SLOTow (๑ orcid.org/0000-0001-9469-1508) AfESG Co-Chair, University of KwaZulu-Natal, Pietermaritzburg, South Africa.E-mail slotow@ukzn.ac.za

This is an Open Access article, distributed under the Creative Commons Attribution license CC BY 4.0

\section{Drones for conservation: new techniques to monitor muriquis}

The northern muriqui Brachyteles hypoxanthus and southern muriqui Brachyteles arachnoides are Critically Endangered primates endemic to the Atlantic Forest of south-east Brazil (Ferraz et al., 2019, The IUCN Red List of Threatened Species, e.T2994A17927482; Talebi et al., 2019, The IUCN Red List of Threatened Species, e.T2993A17927228). In 2017, we developed a novel drone, which we named Dronequi, an S9oo hexacopter from DJI equipped with a GoPro Hero $44 \mathrm{~K}$ camera and a thermal camera (Flir Vue Pro 336 13mm). During 2018-2019, we flew more than 100 hours in various areas, recording B. hypoxanthus on at least five separate occasions. At Parque Estadual Serra do Brigadeiro, Minas Gerais, we counted at least 22 individuals in just 8 minutes of flight, c. $7 \%$ of the population estimated during $>1,700$ hours of fieldwork over a 2-year period.
More recently we acquired a DJI Matrice 200, which we named Dronequi 2.0, equipped with a DJI Zenmuse XT2 that combines a ${ }_{4} \mathrm{~K}$ visual camera and a Flir Tau 2 thermal sensor. With this we surveyed a total of five sites in January, February, August and November 2020, identifying one previously unconfirmed $B$. arachnoides population, one new group, and two other groups already known at sites previously studied by other researchers, in São Paulo, and rediscovering a population of 15 individuals at Peçanha in Minas Gerais. Thus, in 2020 at least five groups of muriquis were detected by drone, with up to 80 individuals counted, in some cases identified to age and sex classes. This was possible because the hybrid camera recorded thermal and colour images simultaneously. An intelligent algorithm, named Murilabs, developed by Storm Group, analyses thermal impressions captured by the drones to identify primate species. This software currently focuses on Brachyteles spp. but could be developed for other primate species.

We have also recorded groups of black capuchin monkeys Sapajus nigritus with sufficient resolution to count individuals. For both capuchin monkeys and muriquis, we can sometimes see infants carried on females' backs, even in large tracts of dense forest. Despite the high cost of thermal cameras for drones, they are efficient and improve surveying and monitoring success for large-bodied Neotropical primates and could potentially be used to detect smaller understorey species in more sparse or riparian vegetation.

Financial support was provided by Boticário Group Foundation for Nature Protection and Vale S.A.

Fabiano RodRIGUES DE MELO (๑ orcid.org/0000-0001-99582036) Departamento de Engenharia Florestal, Universidade Federal de Viçosa, Viçosa, Minas Gerais, Brazil E-mail frmelo@ufv.br

This is an Open Access article, distributed under the Creative Commons Attribution license CC BY 4.0.

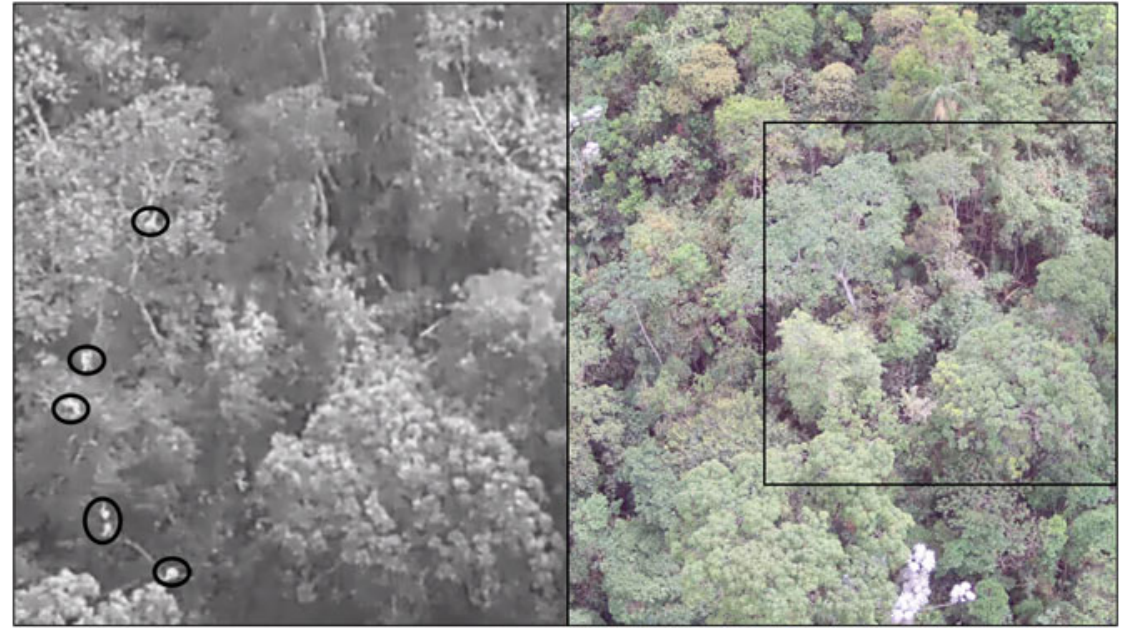

Southern muriquis Brachyteles arachnoides in Pindamonhangaba, São Paulo, recorded by Dronequi 2.0 in November 2020. The black circles on the left-hand image show five muriquis that could only be detected with the infra-red camera. In the visible light image on the right they are not visible. The black rectangle on the right-hand image is the area seen by the thermal camera. (Photos: F.R. de Melo) 